\title{
Nutrition Knowledge and its Impact on Food Choices among the students of Saudi Arabia.
}

\author{
Suneetha Epuru ${ }^{1}$, Mashael Usweed Humaid Al Shammary ${ }^{2}$ \\ ${ }^{1,2}$ (Clinical Nutrition Department, College of Applied Medical Sciences/ University of Hail, Saudi Arabia)
}

\begin{abstract}
:
Background: Food choices vary widely depending on various influencing factors.

Objectives: The aim of this study is to assess the current nutrition knowledge and their impact on food choices and dietary practices in a sample of subjects from the University of Hail (UOH).

Methods: A cross-sectional survey was conducted using online UOH student forum. 100 students participated in the study (males 45 and females 55). The subjects were surveyed through a previously standardized questionnaire for questions related to their nutrition knowledge and awareness along with behaviours related to food choices.

Results: Obesity prevalence is significantly higher in males as compared to females $(\chi 2=9.465 ; p=0.024)$. Psychological factors like emotions, favourite foods etc. were highly influencing factors rather than physiological or nutritional factors in buying and eating various foods. Majority males depend on internet for health related information. Only around $26 \%$ of males and $32 \%$ of females believe that they have adequate nutrition education. Obese group significantly believes that they don't have enough nutrition knowledge $(\chi 2=$ 7.928; $p=0.048)$ or neither consider themselves healthy $(\chi 2=7.970 ; p=0.047)$ as compared to non-obese groups.

Conclusion: Results from this study highlight the importance of early identification of the health risk behaviors in young adults and the need to promote healthy dietary interventions.
\end{abstract}

Keywords: Food Choices, Nutrition Knowledge, Saudi Arabia, Young Adults.

\section{Introduction}

The decision to eat, and to eat particular foods, varies for different individuals and situations. Food choices are influenced by many internal and external cues and are not solely determined by physiological or nutritional needs. Individual differences in food likes and desires develop throughout life because of differing food experiences and attitudes ${ }^{1}$. Some of the factors which influence food choice include: biological determinants such as hunger, appetite and taste; economic determinants such as cost, income, availability; physical determinants such as access, education, skills (eg. cooking) and time; social determinants like culture, family, peers and meal patterns; psychological determinants such as mood, stress, guilty; attitudes, beliefs and knowledge about food ${ }^{2}$.

Given the fact, lifestyle is being more and more identified as important for healthy life; emphasis on proper nutrition is enormously increasing ${ }^{3}$. Nutrition transition has been linked up with growing prevalence rates of non-communicable diseases which are increasingly becoming major mortality causes. Nutrition knowledge plays an important role in raising public awareness and ultimately the health of the society ${ }^{4}$.

Young adults, who are in the process of establishing their own identity apart from parental influence, represent an important transition phase of life and are subject to many influences particularly on dietary behaviours ${ }^{5}$. On the other hand this age also represents an unrealistic sense of optimism concerning the ability to control health believing that they are at lesser risk to hazards as compared to others. This may put them at risk of believing that their dietary quality is high and therefore may not consider healthy eating as an important factor ${ }^{6}$. Knowledge of factors influencing their food choices will hence go a long way in developing effective strategies for health promotion for this age group. In view of the foregoing discussions, the current study was planned with the following specific objectives.

\subsection{Objectives}

- To assess the current nutrition knowledge and practices in a sample of subjects from the University of Hail.

- To study the relationship between nutrition knowledge and food choice patterns.

- To analyze gender specific differences exist between nutrition knowledge, practices and their impact on food choice patterns. 


\section{Methodology}

A cross sectional survey was planned and conducted to assess the nutrition knowledge, practices and their impact on food choice patterns among a random sample of 100 subjects of University of Hail.

\subsection{Design, Sample and Data Collection}

The study design was a cross-sectional survey and was conducted at the University of Hail (UOH) during the winter 2012 -13 semester. Approximately, a random sample size of 100 sample was enrolled in the study by using online student forum. The questionnaires were posted on online student forum for answering with the requisite instructions on how to fill and brief purpose about the study. Answered questionnaires were later downloaded. No personal identification details were collected protecting privacy and allowing for anonymous and voluntary participation. The inclusion criteria included current registration with University of Hail as students, absence of chronic illness, and knowledge of their height, weight information and acceptance of informed consent form. The exclusion criteria included those with less than 18 years and those who are following any special diets, pregnant and lactating mothers.

\subsection{Anthropometry}

The subjects were asked to record their self-reported height and weight information on the questionnaire. Those who were not aware of the information were excluded from the participation of the study. Body Mass Index (BMI) was calculated as the ratio of weight (kilograms) to the square of height (meters). Weight status was classified into four categories: underweight (BMI $\leq 18.5$ ), normal weight (BMI between 18.5 -24.9), overweight (BMI between 25-29.9), and obese (BMI $\geq 30)^{7}$.

\subsection{Assessment Tool}

The questionnaire requested information on socio-demographic and anthropometric information which included age, gender, college, height and weight followed by questions related to study objectives as follows:

Dietary Behaviours, Preferences and knowledge: The participants were asked about their self-perceptions of the adequacy of dietary intake levels of nutrients and other dietary components, awareness of diet-health relationships, perceived importance of following dietary guidance for specific nutrients and other dietary components, behaviours related to food choices. The questionnaire was adopted from a previously published study ${ }^{8}$ and modifications were done on the questionnaire to be more suitable with the dietary and food patterns of the Saudi students.

Validation of the Questionnaire: For content validity (back to back translation), the questionnaire was initially translated into Arabic and then converted back to English and pre-tested for question accuracy and clarity.

\subsection{Statistical Analysis}

The data set was cleaned and edited for inconsistencies. Missing data were not statistically computed. Statistical analyses were performed using the Statistical Package for Social Sciences (version 16.0, SPSS, Inc) software. Descriptive statistics such as means and standard deviations were calculated for the continuous variables and frequencies for qualitative data. Associations were established using chi-square analysis. All reported $P$ values were made on the basis of 2 -sided tests and compared to a significance level of 5\%; differences were considered statistically significant at $\mathrm{P}<0.05$ or $\mathrm{P}<0.01$.

\section{Results}

Table 1 presents the demographic and anthropometric profile of the study subjects $(\mathrm{n}=100)$. The total mean age \pm SD for males $(n=45)$ was $21.27 \pm 1.92$ years (range 18-25) and for females $(n=55)$ was $21.11 \pm 2.07$ years (range 18-25). The mean \pm SD BMI for males was $26.73 \pm 7.57$ which was above international normal range (BMI 18.5 to 25 ) and for females was $24.01 \pm 5.02$ which was closer towards the upper cut-off of the international normal range (BMI 18.5 to 25) ringing alarm bells for the need of immediate preventive initiatives for this population. Fig.1 depicts BMI group distribution between males and females. Obesity prevalence is significantly higher in males as compared to females $(\chi 2=9.465 ; \mathrm{p}=0.024)$.

Table 2 presents the preferences and practices of the subjects related to food habits. Favourite foods were the most important motivating factor for buying foods in both genders as compared to cost or nutrition significance of the foods. Psychological factors like emotions and appeal of the food were triggering factors for the motivation to eat food most times rather than physiological hunger mechanism (56\% vs. $44 \%$ respectively for total subjects). Perceptions of the study subjects indicate that nearly $70 \%$ in both genders believe fruits and vegetables as healthy foods while less than $10 \%$ believe dairy foods goof for health. Around $17 \%$ in both genders are on dieting currently and majority of the study population enjoys cooking (64.44 vs. 72.22 for males and females). 
Table 3 suggests that around $60 \%$ of the subjects prefer eating with their friends frequently while atleast 40 $\%$ of the subjects eat atleast once in a day with their families. The Table also discusses the knowledge and preferences for dairy products reflected in the practices of the subjects. Although almost all of the subjects know dairy products are good for bone health and nearly $80 \%$ of males and females indicated that they like dairy products. However, this is not actually reflecting in their eating behaviour which suggests only around $50 \%$ of males and $60 \%$ of females include them in their daily diet.

Table 3 and Fig. 2 present the details related to soft drink consumption habit and their relation to BMI in study population. Around $50 \%$ of the study population had indicated that they have the habit of consuming soft drinks daily. The noteworthy point is only around $50 \%$ of the study population had also indicated that they drink milk or dairy products daily suggesting that dairy products are being replaced by soft drinks. Analysis (Fig.2) of soft drink consumption pattern and its association with BMI clearly poses a significant relationship between increasing obesity with soft drink habit $(\chi 2=8.141 ; \mathrm{p}=0.043)$. Also further analysis with milk consumption habit with BMI clearly indicates less consumption habit in obese groups as compared to non-obese groups although the differences were not significant (Data not presented).

Table 4 presents the nutrition knowledge of the subjects. Only $40 \%$ of males and $37 \%$ of females believe that skipping breakfast can put them at the risk of obesity. In practice also we can observe nearly $31 \%$ of males and 40 percent of females are at risk of skipping breakfast on most days in a week. Fig. 3 clearly indicates the implications of this perception as non-obese group skip breakfast significantly as compared to obese group $(\chi 2=$ $14.401 ; \mathrm{p}=0.025)$. Similarly knowledge of possibility of consuming higher calories unknowingly when watching TV is reflected in their behaviour. Females who were more cautious to eat when watching TV as compared to males $(66.7 \%$ vs. 72.7$)$ were also significantly $(\chi 2=4.125 ; \mathrm{p}=0.042)$ aware of the consequences of eating while watching TV. Although both genders universally believed that fruits were good suppliers of vitamins and minerals, only $80 \%$ of males and $90 \%$ of females preferred them as snack alternatives as compared to other fast foods.

Table 5 presents beliefs about nutrition education and health perceptions of study subjects. Around $90 \%$ of males depend on internet for health related information whereas this percent is comparatively less in females being just at $75 \%$ as the remaining female subjects depend on books and journals along with health professionals for health related information. Almost all the subjects feel that there is a definite need for nutrition education while only around $26 \%$ of males and $32 \%$ of females felt they have adequate nutrition education. Females were less likely to believe that they are healthy as compared to males (33 vs. $42 \%$ ) while they were more willing to agree that nutrition knowledge will help in making healthy food choices (70 vs. $58 \%)$. Females were also likely to look more for caloric information while males prefer to focus on both caloric as well as other specific nutrients like fats, salt, vitamin and mineral information as well. All the trends mentioned in table 5 were however not statistically significant.

Fig.4 presents beliefs about nutrition education and health perceptions of study subjects according to BMI groups. Obese group significantly believes that they don't have enough nutrition knowledge $(\chi 2=7.928 ; \mathrm{p}$ $=0.048)$ and consider themselves as unhealthy $(\chi 2=7.970 ; \mathrm{p}=0.047)$ as compared to non-obese groups.

\section{Discussion}

The objective of this cross-sectional study was to identify and analyse gender specific differences existing between nutrition knowledge, practices and their impact on food choice patterns. As expected, both genders were at risk of unhealthy dietary habits and poor nutritional knowledge and awareness influencing their food choices and dietary preferences. Eating patterns although dominated by individual taste preferences are subtly influenced by a complex mix of personal, social, cultural, economic and environmental factors ${ }^{9}$.

Changing paradigms in health parameters of young adults emphasize the need for strengthening good health and dietary behaviours among them for optimum health and well-being. Health and dietary patterns which are shaped during young ages are influenced by behavioural choices and environmental factors. In general, young adults are frequently identified as being at risk of malnutrition, largely because of their very high nutrient demands which often appear incompatible with their range of food choices and eating patterns. Coupled with these are the influences of body image and media on their food choices. Ensuring that healthy behaviours are deepened in them during this transition phase is therefore very critical for their overall adult health life and well-being.

There are several emerging health issues which matters specifically for young adults. Firstly, increasing overweight prevalence in them is a concern since longitudinal epidemiological studies provide evidence that obesity, hypercholesterolemia, and hypertension track from early lifestyle choices into adulthood ${ }^{10}$. Furthermore, overweight adolescents are likely to remain as overweight adults ${ }^{11}$. Secondly, Gender differences in dietary intake emerge as compared to childhood during which the food intake of girls and boys tend to be similar ${ }^{12}$. 
BMI is an important indicator of health status. In the present study, obesity prevalence was significantly higher in males as compared to females in accordance with previous studies ${ }^{13}$. Another way of understanding young adult's health status is to examine their eating behaviours and nutrition knowledge.

The present study trends indicate dieting, skipping breakfast behaviour, higher psychological influences rather than physiological influence on buying and eating patterns. The perceptions about their health status and nutrition knowledge also suggest low confidence level especially among the obese subjects highlighting the importance of urgent need for proper nutrition education intervention in this population. Gender differences were also observed for the breakfast consumption patterns from the results of the study which is in support of previous studies ${ }^{14}$. When it comes to carbonated beverage consumption, an alarming $50 \%$ of students usually drank soft drinks. Soft-drink consumption peaks from adolescence and milk intake is at its lowest level ${ }^{15}$ and the present study also found similar confounding results.

The present study being a cross sectional study has limitations in identifying the causal inferences. Also the sample size of the study is small. Future similar studies are essential for understanding gender differences in food choices and their influencing factors.

\section{Conclusions}

Results from this study highlight the importance of early identification of the health risk behaviors in young adults and the need to promote healthy dietary interventions. Education and behavior change programs to promote healthful dietary choices should be based on nutrition knowledge regarding the gender, cultural and psychological factors affecting choices of the students. A higher percent prevalence of health risk behaviours like breakfast skipping, low intake of milk coupled with high soft drink and fast food culture among the study adolescents indicates an alarming situation towards their future health status. Gender differences exist for health risk behaviors and health promoting behaviors; knowledge of which facilitates framing gender specific interventions. Health education campaigns, which raise the knowledge on risk factors and unhealthy behaviors among youth's can educate and self-guard.

\section{References}

[1]. Mela DJ. Determinants of food choice: relationships with obesity and weight control. Obes Res. 2001; Nov 9: Suppl 4: 249S-255S.

[2]. http://www.eufic.org/article/en/expid/review-food-choice/. Accessed on Mar, 15th, 2013.

[3]. Tippett KS, Yasmin SC. Design and operation: the Continuing Survey of Food Intakes by Individuals and the Diet and Health Knowledge Survey, 1994-1996. U S Department of Agriculture, Agricultural Research Service, Nationwide Food Surveys report No 96-1. 1998

[4]. Beydoun MA, Wang Y. Do nutrition knowledge and beliefs modify the association of socio-economic factors and diet quality among US adults? Prev Med. 2008; 46(2): 145-153.

[5]. Ma J, Betts NM, Horacek T, Georgiou C, White A. Assessing stages of change for fruit and vegetable intake in young adults: a combination of traditional staging algorithms and food-frequency questionnaires. Health Educ Res. 2003; 18(2): $224-36$.

[6]. Gibney MJ. European consumers' attitudes and beliefs about safe and nutritious foods: concepts, barriers and benefits. In Proceedings of the International Food Conference: 'Thinking beyond tomorrow' held in Dublin June '2004.

[7]. Clinical guidelines on the identification, evaluation, and treatment of overweight and obesity in adults-the evidence report. National Institutes of Health. Obesity Research. 1998; (Suppl 2): 51S-209S.

[8]. Yahia N, Achkar A, Abdallah A, Rizk S. Eating habits and obesity among Lebanese university students. Nutr J. 2008 ; Oct 30; 7:32.

[9]. Savage JS, Fisher JO, Birch LL. Parental influence on eating behavior: conception to adolescence. J Law Med Ethics. 2007; Spring;35(1): 22-34.

[10]. Wang Y, Chen X. Between-group differences in nutrition- and health-related psychosocial factors among US adults and their associations with diet, exercise, and weight status. $J$ Acad Nutr Diet. 2012; Apr;112(4): 486-498.e3. doi: 10.1016/j.jand.2011.12.003.

[11]. Institute of Medicine. Preventing Childhood Obesity: Health in the Balance. Washington, DC: The National Academies Press. 2005.

[12]. Gleason P, Suitor C. Children's Diets in the Mid-1990s: Dietary Intake and Its Relationship with School Meal Participation. Report No. CN-01-CD1. Alexandria, VA: Office of Analysis, Nutrition and Evaluation, Food and Nutrition Service, U.S. Department of Agriculture. 2001.

[13]. Al-Rethaiaa AS, Fahmy AE, Al-Shwaiyat NM. Obesity and eating habits among college students in Saudi Arabia: a cross sectional study. Nutr J. 2010; Sep 19: 9:39

[14]. Rampersaud GC, Pereira MA, Girard BL, Adams J, Metzl JD: Breakfast habits, nutritional status, body weight, and academic performance in children and adolescents. Journal of American Dietetics Association. 2005; 105: 743-760.

[15]. Forshee RA, Storey ML. Total beverage consumption and beverage choices among children and adolescents. International Journal of Food Science and Nutrition. 2003; 54: 297-307. 
Nutrition Knowledge and its Impact on Food Choices among the students of Saudi Arabia.

Table 1: Demographic and Anthropometric Profile of the Study Population

\begin{tabular}{|l|l|c|c|c|c|c|}
\hline Variables & Gender & Minimum & Maximum & Mean & $\begin{array}{c}\text { Standard } \\
\text { Deviation }\end{array}$ & $\begin{array}{c}\text { T- Value } \\
(* \mathbf{P}<\mathbf{0 . 0 5})\end{array}$ \\
\hline \multirow{2}{*}{ Age (years) } & Males & 18 & 25 & 21.27 & 1.92 & 0.384 \\
& Females & 18 & 25 & 21.11 & 2.07 & \multirow{2}{*}{$3.350^{*}$} \\
\hline \multirow{2}{*}{ Weight $(\mathrm{kg})$} & Males & 42 & 122 & 73.36 & 23.85 & \\
\cline { 2 - 6 } & Females & 37 & 113 & 60.44 & 13.97 & \\
\hline \multirow{2}{*}{ Height $(\mathrm{cm})$} & Males & 142 & 183 & 164.89 & 10.73 & $3.864 *$ \\
\cline { 2 - 6 } & Females & 145 & 175 & 158.46 & 5.35 & \\
\hline \multirow{2}{*}{ BMI $(\mathrm{kg} / \mathrm{m} 2)$} & Males & 16 & 43 & 26.73 & 7.57 & $2.139 *$ \\
& Females & 17 & 41 & 24.01 & 5.02 & \\
\hline
\end{tabular}

Table 2: Preferences and Practices of Subjects related to Food Habits (\%)

\begin{tabular}{|c|c|c|c|}
\hline \multirow{2}{*}{\multicolumn{2}{|c|}{ Variables }} & \multicolumn{2}{|c|}{ Gender } \\
\hline & & Males & Females \\
\hline \multirow{5}{*}{$\begin{array}{l}\text { When buying foods you look } \\
\text { for }\end{array}$} & cost & 13.33 & 3.70 \\
\hline & taste & 11.11 & 18.52 \\
\hline & nutrition labels & 2.22 & 5.56 \\
\hline & healthy foods & 8.89 & 5.56 \\
\hline & favourite foods & 64.44 & 66.67 \\
\hline \multirow[t]{2}{*}{ Usually eat when } & Hungry & 48.89 & 40.74 \\
\hline & have appetite & 51.11 & 59.26 \\
\hline \multirow{3}{*}{$\begin{array}{l}\text { Which foods you feel are } \\
\text { healthy }\end{array}$} & Cereals and Meats & 22.22 & 20.37 \\
\hline & Fruits and Vegetables & 71.11 & 75.93 \\
\hline & Dairy products & 6.67 & 3.70 \\
\hline \multirow[t]{2}{*}{ Are you on Dieting } & Yes & 17.78 & 16.67 \\
\hline & No & 82.22 & 83.33 \\
\hline \multirow[t]{2}{*}{ Do you cook } & Yes & 64.44 & 72.22 \\
\hline & No & 35.56 & 27.78 \\
\hline
\end{tabular}

Table 3: Eating practices of study subjects (\%)

\begin{tabular}{|c|c|c|c|}
\hline \multicolumn{2}{|l|}{ Variables } & \multicolumn{2}{|c|}{ Gender } \\
\hline & & \multirow{2}{*}{$\begin{array}{c}\text { Males } \\
61.36\end{array}$} & \multirow{2}{*}{$\frac{\text { Females }}{62.96}$} \\
\hline Frequent eating with friends & Yes & & \\
\hline & No & 38.64 & 37.04 \\
\hline \multirow[t]{3}{*}{ No. of Meals Eaten with Family } & 1 & 45.45 & 45.28 \\
\hline & 2 & 29.55 & 41.51 \\
\hline & 3 & 25.00 & 13.21 \\
\hline \multirow[t]{2}{*}{ Frequently eating outside } & Yes & 44.44 & 46.30 \\
\hline & No & 55.56 & 53.70 \\
\hline \multirow[t]{2}{*}{ Do you eat or drink daily dairy products } & Yes & 51.11 & 61.11 \\
\hline & No & 48.89 & 38.89 \\
\hline \multirow[t]{2}{*}{ Do you drink soft drinks daily } & Yes & 45.45 & 52.83 \\
\hline & No & 54.55 & 47.17 \\
\hline \multirow{2}{*}{$\begin{array}{l}\text { Do you know milk and other dairy products are } \\
\text { important for bone health }\end{array}$} & Yes & 97.78 & 98.08 \\
\hline & No & 2.22 & 1.92 \\
\hline \multirow[t]{2}{*}{ Do you like milk and other dairy products } & Yes & 82.22 & 77.78 \\
\hline & No & 17.78 & 22.22 \\
\hline
\end{tabular}


Table 4: Nutrition Knowledge of study subjects (\%)

\begin{tabular}{|c|c|c|c|}
\hline \multicolumn{2}{|l|}{ Variables } & \multicolumn{2}{|c|}{ Gender } \\
\hline & & Males & Females \\
\hline \multirow{2}{*}{$\begin{array}{l}\text { Do you know skipping breakfast may put at risk of } \\
\text { obesity }\end{array}$} & Yes & 40.00 & 37.04 \\
\hline & No & 60.00 & 62.96 \\
\hline \multirow[t]{3}{*}{ In a week how many days you eat breakfast } & $\leq 3$ days in a week & 31.11 & 40.74 \\
\hline & $\begin{array}{l}\text { Atleast } 4 \text { or } 5 \text { days in a } \\
\text { week }\end{array}$ & 20.00 & 31.48 \\
\hline & All seven days & 48.89 & 27.78 \\
\hline \multirow[t]{2}{*}{ Do you like to eat while watching TV } & Yes & 72.7 & 66.7 \\
\hline & No & 27.3 & 33.3 \\
\hline \multirow{2}{*}{$\begin{array}{l}\text { Are you aware that you may consume more calories } \\
\text { when watching TV }\end{array}$} & Yes & 33.33 & 53.70 \\
\hline & No & 66.67 & 46.30 \\
\hline \multirow{2}{*}{$\begin{array}{l}\text { Do you read nutritional label information when you } \\
\text { are buying foods }\end{array}$} & Yes & 53.33 & 46.30 \\
\hline & No & 46.67 & 53.70 \\
\hline \multirow{2}{*}{$\begin{array}{l}\text { Do you think fruits supply us with vitamins and } \\
\text { minerals }\end{array}$} & Yes & 100.00 & 100.00 \\
\hline & No & .00 & .00 \\
\hline \multirow{2}{*}{$\begin{array}{l}\text { Do you think vegetables supply us with vitamins } \\
\text { and minerals }\end{array}$} & Yes & 91.11 & 98.15 \\
\hline & No & 8.89 & 1.85 \\
\hline \multirow{2}{*}{$\begin{array}{l}\text { Do you prefer to buy fruits / } 100 \% \text { fruit juices as } \\
\text { snacks }\end{array}$} & Yes & 80.00 & 90.74 \\
\hline & No & 20.00 & 9.26 \\
\hline
\end{tabular}

Table 5: Beliefs about Nutrition Education and Health Perception of study subjects (\%)

\begin{tabular}{|c|c|c|c|}
\hline \multicolumn{2}{|l|}{ Variables } & \multicolumn{2}{|c|}{ Gender } \\
\hline & & \multirow{2}{*}{$\begin{array}{c}\text { Males } \\
91.11\end{array}$} & \multirow{2}{*}{$\begin{array}{c}\text { Females } \\
75.93\end{array}$} \\
\hline If you want to know about healthy diet related & Internet & & \\
\hline information where do you look for & $\begin{array}{l}\text { Books/Magazines/ } \\
\text { Journals }\end{array}$ & 2.22 & 11.12 \\
\hline & Health Authorities & 6.67 & 12.96 \\
\hline \multirow[t]{2}{*}{ Do you feel there is a need for nutrition education } & Yes & 97.78 & 100.00 \\
\hline & No & 2.22 & 0.00 \\
\hline \multirow[t]{2}{*}{ Do you feel your nutrition knowledge is adequate } & Yes & 26.67 & 31.48 \\
\hline & No & 73.33 & 68.52 \\
\hline \multirow[t]{2}{*}{ Do you consider yourself healthy person } & Yes & 42.22 & 33.33 \\
\hline & No & 57.78 & 66.67 \\
\hline \multirow{2}{*}{$\begin{array}{l}\text { Do you think your nutrition knowledge help you } \\
\text { make healthy food choices }\end{array}$} & Yes & 57.78 & 70.37 \\
\hline & No & 42.22 & 29.63 \\
\hline \multirow{2}{*}{$\begin{array}{l}\text { What nutrition label information you would } \\
\text { specifically look for }\end{array}$} & Calories & 57.69 & 61.54 \\
\hline & $\begin{array}{l}\text { Nutrient Specific } \\
\text { Information }\end{array}$ & 42.31 & 38.46 \\
\hline
\end{tabular}

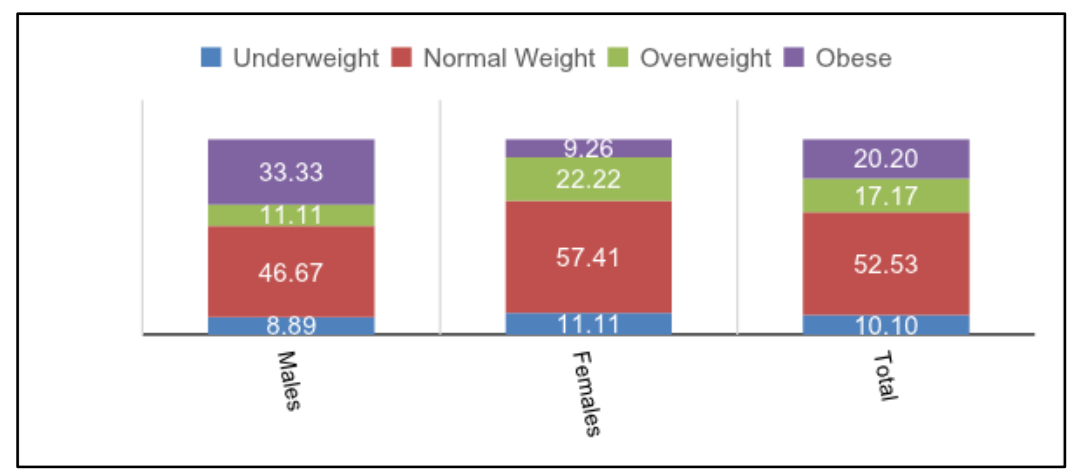

Fig.1: Gender and BMI Group Distribution among the Study Population 


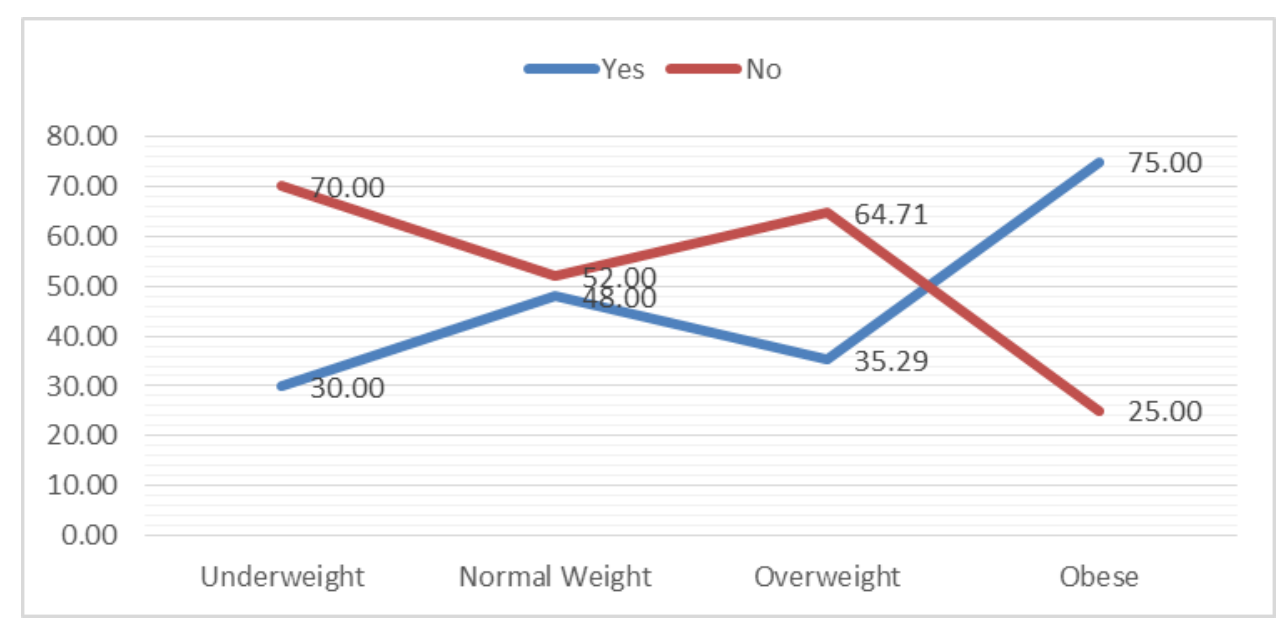

Fig. 2: Soft Drink Consumption Habit and BMI Group Distribution among the Study Population (\%)

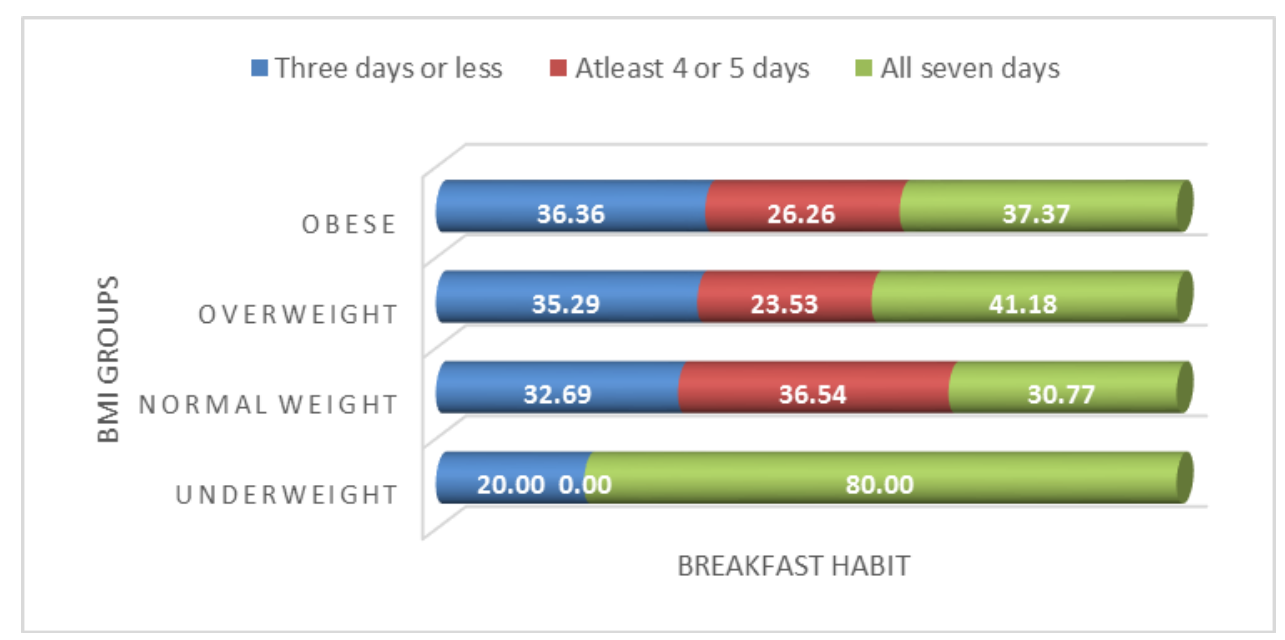

Fig.3: BMI Groups and Breakfast Eating Habit among the Study Population

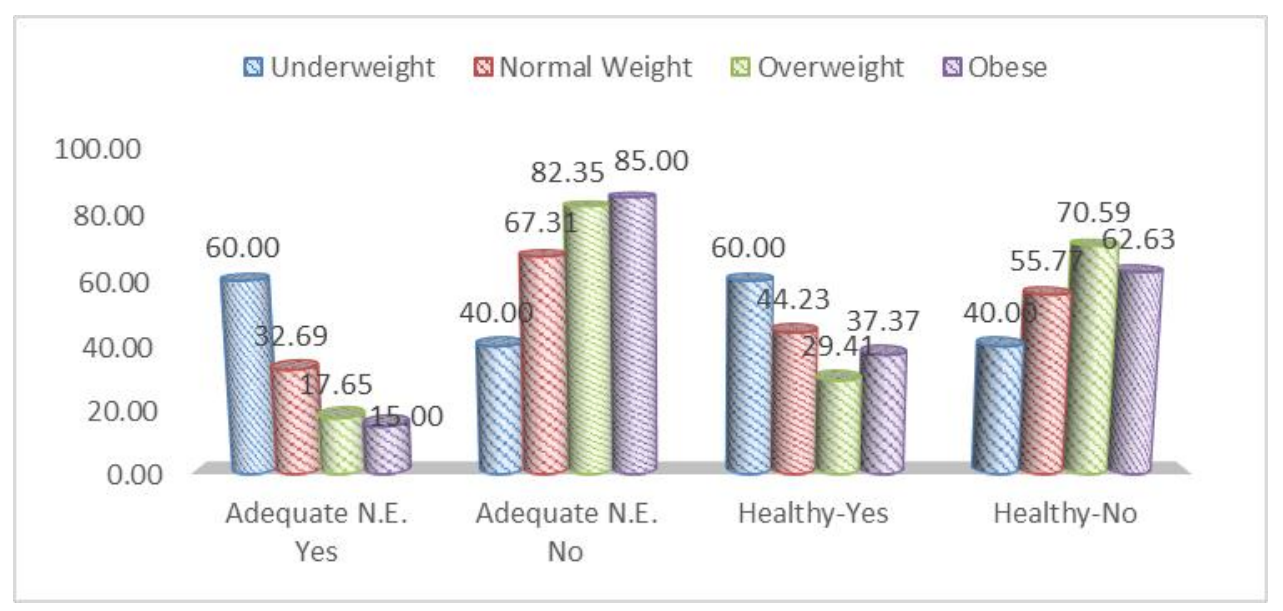

Fig.4: Beliefs about Nutrition Education and Health Perception of study subjects according to BMI groups 